\title{
Sebastián León
}

Pontificia Universidad Católica del Perú

https://doi.org/l0.18800/estudiosdefilosofia.201701.002

Resumen: El presente trabajo busca aproximarse a dos concepciones distintas sobre la llustración y la modernidad. La primera parte considera la comprensión del filósofo francés Michel Foucault sobre la modernidad como una "actitud" o ethos crítico de la propia época, que pasa necesariamente por una problematización de aquello que en distintos procesos contingentes hemos llegado a ser (cómo nos hemos constituido como sujetos); la segunda parte se enfoca en la propuesta del alemán Jürgen Habermas, que invita a comprender la modernidad como un "proyecto inacabado", como un cierto potencial o ideal racional aún por realizar. Hacia el final del ensayo se confrontan ambas posturas, tratando de que emerja un diálogo productivo que nos permita rescatar elementos de cada proyecto y planteando algunas críticas y observaciones soore las concepciones sociohistóricas de cada autor.

Palabras clave: crítica, modernidad, libertad, poder, racionalidad.

Abstract: "On the Critical Legacy: Two Perspectives on Enlightenment". The present essay approaches two different conceptions of Enlightenment and modernity. The first part considers Michel Foucault's understanding of modernity as an "attitude" or "critical ethos" belonging to that age, that necessarily questions that which we have come to be in various contingent processes (how we have constituted ourselves as subjects); the second part considers Jürgen Habermas's proposal, which invites us to understand modernity as an "unfinished project", as a certain potential or rational ideal that is still to be carried out. Towards the end of the essay both stances are confronted, whereby an attempt is made to engage elements retrieved from each in a productive dialogue, and to raise some criticisms and observations regarding the sociohistorical conceptions of each author.

Keywords: critique, freedom, modernity, power, rationality. 


\section{$\S 1$. Saber, poder, ética: la ontología histórica del presente como ethos de la Ilustración}

Foucault aclara, en la Introducción a La arqueología del saber, su posición frente a la historia: no buscará reconstruir una linealidad racional y progresiva en la historia del saber, sino que, a partir del estudio de documentos de un cierto período, buscará reconstruir su lógica interna, la manera en que encajan en una red de relaciones, estableciendo así series diferenciadas a modo de sistemas. Foucault concibe la historia como una serie de cortes e interrupciones, distintos momentos históricos con su propia racionalidad y especificidad, y no como un progreso continuo en el que cada momento pasado refleja el presente, como si la historia fuera el trayecto de una misma conciencia o de un mismo "macrosujeto" (Foucault 2002, 3-5).

Esto se hace patente en el hecho de que, para Foucault, nuestros enunciados' no serían equivalentes en una época o en otra, ni serían el mero refinamiento de un saber heredado. Más bien, un enunciado cualquiera no podría entenderse aislado de un cierto marco de reglas específicas que lo determinan y lo hacen posible; estas reglas serían siempre contextuales e históricas, en tanto que no ocuparían un lugar trascendente con respecto a los hechos (a la usanza kantiana), sino que se producirían en la propia realidad histórica. Es

I Hay que tener presente lo que Foucault tiene en mente cuando habla de "enunciados". Foucault, así como varios especialistas en su obra como Hubert Dreyfus y Paul Rabinow (1983, 45-46) y Gary Gutting (1989, 239-242), señala que no se trata de meras proposiciones lingüísticas - lógicas. Para Gutting, Dreyfus y Rabinow, los enunciados de Foucault serían equivalentes a los "actos de habla" (speech acts) de la filosofía anglosajona del lenguaje ordinario o del lenguaje realizativo (performative): no se trataría de una concepción meramente propositiva del lenguaje, sino de una reflexión sobre cómo los seres humanos podemos hacer cosas, relacionarnos de distintos modos entre nosotros y con nuestro medio, empleando el lenguaje. Foucault mismo destaca en La arqueología del saber la similitud entre lo que él llama enunciados y los actos de habla: "iNo podría decirse que existe enunciado siempre que se puede reconocer y aislar un acto de formulación, algo así como speech act, ese acto 'elocutorio' de que hablan los analistas ingleses?" (Foucalut 2002, 137). Acto seguido, el autor pasa a hacer una distinción entre ambos, señalando que, tal como él lo entiende, un acto de habla no puede componer junto con otros tipos de acto de habla un acto más complejo, cosa que sí sería posible con los enunciados (Foucalut 2002, 138-139). Sin embargo, en su correspondencia con Foucault, el estadounidense John Searle le señala que en la teoría de actos de habla, varios actos de habla de distinto tipo podrían componer otro distinto, por lo que Foucault acaba admitiendo: "En lo que respecta al análisis de los actos de habla, estoy completamente de acuerdo con tus observaciones. Estaba equivocado al señalar que los enunciados no son actos de habla (...)” (Dreyfus y Rabinow 1983, 46, pie de página). 
por ello que Foucault hablará de "aprioris históricos" como condición de todo enunciado posible al interior de una cierta unidad de saber (Foucault 2002, 214-223). Por ejemplo: “(...) en determinada escala de la macrohistoria, se puede considerar que una afirmación como 'Las especies evolucionan' forma el mismo enunciado en Darwin y en Simpson; a un nivel más fino, y considerando campos de utilización más limitados (el 'neo-darwinismo' por oposición al sistema darwinista propiamente dicho), se trata de dos enunciados diferentes. La constancia del enunciado, la conservación de su identidad a través de los acontecimientos singulares de las enunciaciones, sus desdoblamientos a través de la identidad de las formas, todo esto es función de campos de utilización en los que se encuentra inserto" (Foucault 2002, 175).

Así pues, incluso dos proposiciones idénticas se usarían de un modo distinto dentro de marcos de reglas epistémicas distintos, adquiriendo cada una un sentido diferente, ininteligible fuera de su respectivo marco. Por esta razón, se constituirían como dos enunciados distintos. Ahora bien, como se ha mencionado, la labor arqueológica de Foucault consistiría en reconstruir dichas reglas en la aproximación a documentos relativos a un cierto campo de saber, perteneciente a un determinado período histórico. En la reconstrucción del a priori histórico se abstraerá de detalles biográficos sobre los autores, comentarios e interpretaciones posteriores a sus obras, etc.: el análisis arqueológico no buscará desentrañar significados ocultos expresados en los documentos, atisbos de interioridad alguna, sino que se limitará a trabajar con los documentos con la finalidad de desentrañar la lógica que hizo posibles los discursos de los que forman parte (Foucault 2002, 9- II)². Por la misma razón, los saberes no representarían hechos u objetos externos a los discursos, sino que sus objetos emergerían de acuerdo a la lógica arqueológicamente explicitada, fuera de la cual resultarían ininteligibles. Que las reglas de un campo discursivo determinen modos de razonamiento específicos se deberá a especificidades en sus prácticas históricas: así, en un contexto donde no han aparecido metodologías estadísticas, las normas epistémicas no permitirían evaluar la corrección de enunciados como "hay $20 \%$ de probabilidades de

2 Es importante mencionar que, para Foucault, resulta imposible para el teórico reconstruir a cabalidad por la vía arqueológica su propio a priori histórico. A mi juicio, esto se hace evidente por la propia metodología del autor. 
que llueva mañana"3; o, en un ejemplo más cercano a Foucault, no podría pensarse la locura como patología ni como atenuante de un crimen donde no ha surgido la práctica psiquiátrica moderna. En palabras del autor, los objetos de un cierto discurso epistémico pueden emerger porque al interior de dicho discurso "(...) se ha hecho obrar un conjunto de relaciones determinadas (...)" (Foucault 2002, 7l): la mencionada posibilidad de pensar la locura como el atenuante de un crimen solo será posible por las relaciones existentes entre la práctica psiquiátrica y la práctica jurídica modernas. Asimismo, serán estas "relaciones discursivas" (Foucault 2002, 75) ${ }^{4}$ las que le permitan a Foucault hablar de cuerpos de saber o unidades discursivas ("la psicopatología”), puesto que ya no podrán identificarse del lado de supuestos objetos extradiscursivos (Foucault 2002, 76) .

Más adelante me gustaría hablar sobre los movimientos, cambios y enfrentamientos que pueden darse al interior de un campo de saber determinado, pero por ahora me conformaré con recapitular, señalando que lo que para Foucault nos permitiría la labor arqueológica es comprender qué es lo que puede pensarse, hacerse o decirse en un determinado momento histórico, cuáles serían las posibilidades, las diferentes "posiciones de sujeto" que los individuos involucrados en ciertas prácticas discursivas históricamente constituidas pueden adoptar. Pienso que es aquí donde se hace pertinente hablar de la posición de Foucault respecto a la modernidad y la llustración. Tras algunas reflexiones sobre "¿Qué es la llustración?” de Kant, hacia la mitad de su texto del mismo nombre, Foucault plantea lo siguiente: "Frecuentemente se habla de la modernidad como de una época, o al menos, como un conjunto de rasgos característicos de una época; suele situársela en un calendario en el que aparecería precedida por una pre-modernidad más o menos ingenua o arcaica, y seguida por una enigmática e inquietante 'post-modernidad'. (...) [M] pregunto si no se puede considerar a la modernidad más bien como una

3 El ejemplo es de Joseph Rouse, que sigue aquí la noción de "estilos de razonamiento" de lan Hacking (Rouse 2005, II7, pie de página).

4 Estas relaciones, explica Foucault, no son meramente "lingüísticas", sino que involucran articulaciones entre dispositivos y prácticas concretas.

5 A partir de esta intuición de Foucault, se hace patente que, para él, un saber no se reduciría a un conjunto de enunciados y sus respectivos objetos de conocimiento, sino que su campo abarcaría prácticas específicas, instrumentos, programas de investigación, habilidades, redes sociales e instituciones (Rouse 2005, II3). 
actitud que como un período de la historia. Con 'actitud' quiero decir un modo de relación con y frente a la actualidad; una decisión voluntaria que algunos toman; en suma, una manera de pensar y de sentir, una manera, también, de actuar y de conducirse que marca una relación de pertenencia y, simultáneamente, se presenta a sí misma como una tarea. (...) [M]ás que querer distinguir el 'período moderno' de las épocas 'pre' o 'post-moderna', creo que sería mejor indagar sobre cómo la actitud de modernidad, desde su propia formación, se encuentra en luchas con actitudes de 'contra-modernidad'" (Foucault 1994, 8, cursivas añadidas) ${ }^{6}$. Pienso que es crucial destacar que, para Foucault, la modernidad no es algo que nos ocurre pasivamente, no es meramente hallarnos, por destino o por azar, en este momento histórico específico como en un atolladero. Más bien se trataría de una actitud, de una práctica ética en la que nos involucramos por una decisión voluntaria: el ser moderno implica para Foucault un involucramiento activo con nuestro tiempo histórico. Resulta interesante comparar esta comprensión de la llustración con la noción de subjetividad que parecía esbozarse en las consideraciones arqueológicas del autor (posibilidades determinadas o constreñidas por un cierto a priori histórico, suscritas al campo de enunciados y razonamientos posibles que en Las palabras y las cosas Foucault llama "episteme") ${ }^{7}$. Podemos argumentar que hay una distinción al interior de la obra de Foucault (especialmente notoria en sus trabajos tardíos) entre los sujetos enfrentados pasivamente con los procesos y prácticas propios de su tiempo, y aquellos que hacen suya la invitación kantiana a asumir la "mayoría de edad" y se comprometen activamente con el ethos moderno ${ }^{8}$. Foucault mismo reconoce y explicita esta distinción: "Hay dos significados de la palabra sujeto: sometido a otro a través del control y

6 He modificado levemente la traducción de las cursivas. Dávila traduce: "un escogimiento voluntario que algunos hacen".

7 Existen discusiones muy interesantes sobre qué consecuencias tiene para la obra temprana de Foucault su giro hacia la genealogía en la década del 70. Hacia el final de su vida, Foucault parece sugerir que puede entenderse su obra como un todo coherente (Foucault 1988, 3-4). Por razones de espacio no entraré en esa discusión, pero hay trabajos muy interesantes al respecto. Por ejemplo, en un artículo del Cambridge Companion to Foucault, Béatrice Han y Edward Pile plantean que los trabajos genealógicos de Foucault llevan a una anulación de la distinción entre la episteme clásica y la moderna: el famoso "doblete empírico-trascendental" de las palabras y las cosas ya no surgiría con el giro crítico kantiano, sino que hallaría sus raíces en la epistemología cartesiana (Han y Pile 2005, 176-209).

8 Por supuesto, no es una distinción tajante, de carácter ontológico. Quizás sería más preciso decir que, en tanto que se trata de una cuestión ética, de una actitud asumida, el carácter de la distinción es deontológico. 
la dependencia, y sujeto atado a su propia identidad por la conciencia o el conocimiento de sí mismo" (Foucault 1988, 8).

Para que estas ideas se perfilen más claramente, habría que hablar de la segunda metodología crítica desarrollada por Foucault, empleada en sus trabajos de mediados de los 70s en adelante: la genealogía. En un primer momento, Foucault caracteriza el método genealógico como una problematización sobre cuáles han sido los procesos históricos mediante los cuales hemos llegado a ser lo que somos en el presente (Foucault 1994, 14-18). Siguiendo esta pauta, Martin Saar señala que la historización genealógica debe limitarse por principio a un campo específico de objetos, relacionado siempre, de manera directa o indirecta, al devenir histórico de la subjetividad (Saar 2008, 298) ${ }^{9}$. A lo que se apunta es a evidenciar cómo habrían surgido las normas, prácticas sociales e instituciones que habrían dado lugar a los saberes y sentidos comunes de una sociedad y, específicamente, a la autocomprensión de los sujetos con respecto a los límites de aquello que les es posible hacer, decir y pensar de manera lícita. Al develar estos procesos, se buscaría hacer una valoración crítica sobre el presente y abrir el espacio de posibilidades en lo que respecta a aquello que podemos llegar a ser. Es decir, explicitando el origen contingente de normas, prácticas e instituciones, se buscaría evidenciar una grieta en los límites de la racionalidad histórica que permita constituir nuevas formas de subjetividad o agencia individual y colectiva (Owen 1999, 39-40).

El punto de partida de la genealogía en tanto crítica es un estado de cosas en el que las condiciones de la subjetividad se habrían sedimentado, donde las normas sociales habrían adoptado el cariz de lo natural o necesario. Así, por ejemplo, Foucault cuestiona, en el primer volumen de su Historia de la sexualidad, las posiciones psiquiátricas y psicoanalíticas que aceptan una determinada concepción antropológica, supuestamente objetiva, que les permitiría evaluar la normalidad de las prácticas sexuales de los sujetos. Rastreando su origen, buscaría exponer los diversos procesos azarosos, las diversas luchas y fuerzas históricas que de manera contingente habrían confluido para dar forma y apariencia de necesidad a esta concepción específica de la sexualidad,

9 Esto tiene que ver con la afirmación de Foucault de que no podemos nunca conocer a cabalidad cuales son nuestros "límites contingentes", sino únicamente en campos específicos, por medio de un trabajo metódico y paciente (Foucault 1994, 15-18). 
recuperando así la perspectiva histórica perdida. Ahora bien, Saar señala que para cumplir este objetivo, la genealogía debe "(...) describir los fenómenos sociales en términos de poder (...)” (Saar 2008, 298). Foucault señala que el poder: “(...) se enraíza en el cuerpo. (...) [E]s el cuerpo quien soporta, en su vida y su muerte, en su fuerza y en su debilidad, la sanción de toda verdad o error, como lleva en sí también, a la inversa, el origen -la procedencia. (...) El cuerpo: superficie de la inscripción de los sucesos (mientras que el lenguaje los marca y las ideas los disuelven), lugar de disociación del yo (al cual intenta prestar la quimera de una unidad substancial), volumen en perpetuo derrumbamiento. La genealogía, como el análisis de la procedencia, se encuentra por tanto en la articulación del cuerpo y de la historia. Debe mostrar al cuerpo impregnado de historia, y a la historia como destructora del cuerpo" (Foucault 1992, 14-I5).

Para no incurrir en confusiones sobre la práctica genealógica, hay que comprender adecuadamente el concepto de poder que se quiere emplear. No se trataría de una comprensión negativa del poder, a modo de una determinación heterónoma o coactiva sobre la conducta de los individuos (una interrupción de su agencia libre), sino que, para Foucault, el poder tendría un carácter predominantemente ontológico, constitutivo. No estaría reñido con la libertad ni con la racionalidad de los agentes, sino que las presupondría y se implicaría mutuamente con ellas: aquellas cosas que hacen posible que un sujeto llegue a ser lo que es, que sea capaz de hacer y de pensar lo que es capaz de hacer y de pensar, que llegue a comprenderse a sí mismo de cierta manera, que asuma cierta relación consigo mismo y con los demás, estarían atravesadas por dinámicas de poder. Afirma el autor: "Cuando se define el ejercicio del poder como un modo de acción sobre las acciones de los otros (...) se incluye un elemento importante: la libertad. El poder se ejerce únicamente sobre 'sujetos libres' y sólo en la medida en que son 'libres'. Por esto queremos decir sujetos individuales o colectivos, enfrentados en un campo de posibilidades, donde pueden tener diversas conductas, diversas reacciones $y$ diversos comportamientos. (...) [N]o hay una confrontación cara a cara entre el poder y la libertad que sea mutuamente exclusiva (...), sino un juego mucho más complicado. En este juego, la libertad puede muy bien aparecer como condición de existencia del poder (...); pero también aparece como aquello que no podrá sino oponerse a un ejercicio del poder que en última instancia, tiende a determinarla completamente" (Foucault 1988, 16). 
Pienso que este extracto es clave y nos ofrece una de las exposiciones más precisas de la comprensión que tiene Foucault del poder: el poder es un tipo de relación intersubjetiva, en la que uno o más agentes conduce(n) la conducta de otro (u otros). Un ejemplo de esta conducción podría ser el de un estudiante universitario que, por encargo del profesor, debe preparar una exposición: en principio, el estudiante no está obligado a seguir un único curso de acción, pero la indicación del maestro lo conduce en tanto que le abre un cierto espacio de posibilidades en dicho contexto socialmente normado. El estudiante podría preparar la exposición tal como se le indica (a); podría negarse, aduciendo una protesta contra una autoridad arbitraria (b); o podría sencillamente faltar a la clase, exponiéndose a reprobar el curso (c), entre otras posibilidades hipotéticas. En cada caso, no solo habrá actuado libremente, sino que, dependiendo de lo que decida hacer, él también habrá conducido la conducta del maestro, determinando en cierta medida sus posibilidades de reacción, ejerciendo así un contrapoder o resistencia y evidenciando que la dinámica del poder es siempre de ida y vuelta (Ingram 2005, 265). Ahora bien, para terminar de clarificar esta idea, habría que resaltar que, para Foucault, el poder no tiene una estructura meramente diádica; es decir, las relaciones de poder no podrían entenderse simplemente como un ejercicio de poder por parte de un "sujeto A" sobre un "sujeto B". Más bien, volviendo al ejemplo del maestro y su estudiante, el ejercicio del poder se articularía con factores como la presencia de otros estudiantes, el contexto institucional con sus respectivas normas y relaciones jerárquicas, los discursos verdaderos o saberes sobre la pedagogía (y otros relevantes a la situación), entre otros, articulándose dicho espacio como un entramado de relaciones de poder que termina influyendo sobre las respuestas de los agentes o, siguiendo a Foucault, los "disponen estratégicamente" sobre dicho espacio (en otras palabras, las posibilidades abiertas por el ejercicio del poder les permiten disponerse o alinearse de ciertas maneras). Desde esta perspectiva, todo ejercicio individual de poder requeriría que los otros agentes que conforman este entramado de relaciones actúen de manera coordinada (Foucault 2008, 96) ${ }^{10}$.

I0 Soy de la idea de que la noción foucaultiana de estrategia puede comprenderse mejor a partir de la idea de Thomas Wartenberg de que el poder estaría mediado por "alineamientos sociales". Cito aquía Wartenberg: "Un campo de agentes sociales puede constituir un alineamiento con respecto a otro agente social si y solo si, primero que nada, sus acciones en lo que respecta a ese agente están coordinadas de manera específica. Para ser un alineamiento, sin embargo, las prácticas coordinadas de estos agentes sociales necesitan ser lo suficientemente exhaustivas 
Para distinguir esta concepción relacional del poder de la interpretación clásica que lo comprende exclusivamente en términos de dominación, Foucault habla de "poder pastoral" (puesto que la función tradicional de los "pastores" en la comunidad cristiana era conducir las almas de la comunidad de creyentes; Foucault 1988, 8). Sin embargo, este concepto de poder también permite pensar la dominación: tal como la genealogía la entiende, esta se daría en aquellos contextos en los que las relaciones de poder se han "rigidizado", restringiendo a un mínimo las posibilidades de resistencia". Para David Owen, serían los contextos de dominación, evidenciados por la "sensación de impotencia" que experimentan los sujetos que han logrado reconocer la limitación en sus posibilidades de agencia, los que harían legítimas las críticas de carácter genealógico. Sería en ellos donde se hace deseable historizar las prácticas sociales para trazar una línea de fuga, explicitar la contingencia de los límites socialmente impuestos para hacer posible su transgresión; en otras palabras, dinamizar una vez más las relaciones de poder para expandir las posibilidades de agenciay, así, transformar la subjetividad (Owen 1999, 36): “(...) si la pregunta de Kant fue la de saber cuáles son los límites a los que el conocimiento debe renunciar a traspasar, me parece que hoy, la pregunta crítica debe retornar a su forma positiva; a saber, ien lo que nos es dado como universal, necesario, obligatorio, qué lugar ocupa aquello que es singular, contingente y ocasionado por restricciones arbitrarias? Se trata, en suma, de transformar la crítica ejercida en la forma de la limitación necesaria, en una crítica práctica que toma la forma de una transgresión posible" (Foucault 1994, 14).

Ahora bien, si dentro del esquema genealógico la relación entre dos o más individuos es siempre una relación de poder, Foucault define la relación de un individuo consigo mismo (lo que abarca las acciones que ejerce sobre sí mismo) como una relación ética $(O \text { wen } 1999,33)^{12}$. La ética sería, en cierto

como para que el agente enfrentado al alineamiento se encuentre con dicho alineamiento como teniendo control sobre ciertas cosas que él podría necesitar o desear (...). El concepto de un alineamiento social entonces provee de una manera de comprender el 'campo' que constituye una relación de poder situada como una relación de poder" (Wartenberg 1990, 170, la traducción es mía).

II Asimismo, para Foucault, donde no hay ninguna posibilidad de reaccionar libremente, ya no podría hablarse propiamente de poder (Foucault 1999a, 395).

12 En realidad, es impreciso decir que la ética para Foucault se limita a la relación del sujeto consigo mismo, en la medida en que la relación que establece consigo influye directamente en la manera en que se relaciona con los demás. Quizá sería más preciso decir, en los términos 
modo, un ejercicio de poder sobre uno mismo que acabaría por definir la subjetividad de un individuo; para Foucault, la posición ética que uno adopta en la asimilación de las normas y principios sociales puede "fortalecer" la posición dentro de una dinámica intersubjetiva de poder. Por dar un caso, en la Historia de la sexualidad I, al narrar cómo fueron dándose los procesos en que los individuos modernos, por medio del desplazamiento de las prácticas confesionales desde la religión hacia ámbitos como la psiquiatría y la legalidad, comenzaron a constituir su subjetividad en relación a sus prácticas sexuales (esto es, a partir de la exigencia de inspeccionar e identificar sus pensamientos, deseos y placeres particulares, comenzaron a desarrollar una orientación o identidad sexual), podríamos decir que lo que se va delineando es una cierta práctica ética. En el análisis de Foucault, inicialmente, las instituciones médicas y jurídicas catalogan a los sujetos de orientación homosexual como enfermos o anormales, pero eventualmente estos mismos individuos, que aceptan la categoría universal bajo la cual se les agrupa ("homosexuales") y han llegado a identificarse con ella, reivindican su identidad y logran establecer nuevos posicionamientos estratégicos para resistir al poder (Foucault 2008, 89-92). A entender de Saar, precisamente lo que buscaría la genealogía, al fluidizar las relaciones de poder y explicitar la contingencia de normas y prácticas sociales, sería modificar la relación que tienen los lectores de la narrativa genealógica consigo mismos; es decir, transformarlos en un sentido ético (Saar 2008, 313314; Owen 1999, 39-40)13. Esta transformación puede interpretarse a partir del concepto de "libertad expresiva", compartido por autores anglosajones como Owen (2008, 143-167) y Brandom (1979, 187-196): el sujeto que se "libera" en este sentido, no simplemente se despoja de los constreñimientos, quedando enteramente desatado o dueño de una espontaneidad radical e indeterminada, sino que se modifica a sí mismo mediante una apropiación creativa (estratégica) de las normas del espacio social (el ejemplo usado puede entenderse como un proceso en el que empiezan a darse una serie de aplicaciones nuevas de la categoría "homosexual"). Las normas y prácticas sociales se transforman (se amplía el horizonte de la libertad), pero no son simplemente abolidas; por eso, para Foucault, la libertad no debe entenderse

que Foucault toma de la antigüedad, que solo cuidando de la relación consigo mismo el sujeto se hace capaz de cuidar de las relaciones que establece con los demás (estableciendo relaciones responsables).

I3 De hecho, según el propio Foucault, el objeto de sus investigaciones genealógicas era transformarse a sí mismo. 
como una liberación de condicionamientos externos, sino como una práctica (ética) (Foucault 1999a, 394-395) ${ }^{14}$.

Explicada la figura de la dinámica del poder y la comprensión del campo social como un campo estratégico, podríamos acabar este apartado ampliando algunos puntos sobre la concepción del saber que desarrollamos al inicio. Para Joseph Rouse, la especificidad histórica del concepto foucaultiano de saber lo haría análogo al de poder; el rechazo de Foucault a estándares epistémicos universales podría entenderse a partir de su rechazo del poder comprendido como un "poder soberano" (como dominación o coacción de la libertad): buscar un criterio universal, que trascienda los contextos, para evaluar la corrección teórica de los enunciados sería reificar el saber (entenderlo como un punto de vista exterior desde el cual evaluar el valor de verdad de los enunciados) ${ }^{15}$. Para este autor, Foucault comprendería el saber como un campo de relaciones dinámicas (Rouse 2005, 108).

Manteniendo la analogía con el concepto de foucaultiano de poder, al interior de un campo de saber encontraríamos: "La multiplicidad de las relaciones de fuerzas inmanentes y propias del campo en que se ejercen, y que son constitutivas de su organización; el juego que por medio de luchas y enfrentamientos incesantes las transforma, las refuerza, las invierte (...)" (Foucault 1999b, 90). Toda apariencia de permanencia en el saber sería producto de alineamientos estratégicos. Así como un ejercicio de poder solo puede realizarse exitosamente si los agentes del otro polo de la relación se alinean de cierta manera, en concierto con la acción del agente que lo ejerce, las pretensiones de verdad o enunciados autorizados solo son corroborados si se da un alineamiento correspondiente por parte de los otros agentes, en principio predispuestos a validarlos (Rouse 2005, II2-II3). Sin embargo, los agentes siempre pueden resistirse a otorgar tal validación, en la medida en que

14 Esta concepción de la ética como práctica de la libertad recordaría en cierto sentido a la idea aristotélica de virtud, en la cual la virtud debía siempre ejercerse para poder existir. Foucault señala, sin embargo, que habrían ciertos contextos extremos de dominación en los que cabría hablar de liberación en términos de despojarse constreñimientos.

I5 En la tradición que concibe el poder en términos de coacción heterónoma, de Hobbes a Habermas, habría un ámbito incondicionado, puramente normativo, desde el que se podría evaluar la legitimidad de los ejercicios del poder. Como se ha señalado, es contra esa tradición que Foucault propone su concepto relacional del poder. 
sus expectativas frente al saber sean desafiadas; de ser el caso, los agentes pueden realinearse en oposición a los enunciados y prácticas en cuestión, con el objetivo de reconfigurar el saber. Por ello, para Rouse, algunos elementos al interior del campo epistémico (los enunciados, objetos, instrumentos, investigaciones, instituciones, etc.) pueden reforzarse mutuamente (manteniendo en el tiempo su legitimidad), mientras que otros pueden entrar en conflicto con las relaciones estratégicas que se van formando (poniendo su legitimidad en disputa), y otros sencillamente pueden aislarse del conflicto, a riesgo de quedar desfasados u obsoletos (Rouse 2005, II3). Así, los diversos elementos en el campo de saber solo se harían epistémicamente significativos en la medida en que se van usando y progresivamente van conectándose con otros, pero siempre exponiéndose a la posibilidad de entrar en conflicto con prácticas epistémicas emergentes: estas dinámicas agonísticas estimularían nuevas investigaciones, refinamientos técnicos y articulaciones que beneficiarían el constante desarrollo y la reorganización del saber (Rouse 2005, I|3-||4).

Las relaciones de poder y las de saber no serían idénticas, pero, como hemos visto, su carácter estratégico sería muy similar. Asimismo, Foucault resalta que “(...) las relaciones de poder no están en posición de exterioridad respecto a otro tipo de relaciones (procesos económicos, relaciones de conocimiento, relaciones sexuales), sino que son inmanentes; constituyen efectos inmediatos de las particiones, desigualdades y desequilibrios que se producen, y, recíprocamente, son las condiciones internas de tales diferenciaciones (...)" (Foucault 2008 , 90). Cómo se articulan poder y saber variará según cada contexto histórico, pero, como sabemos por la obra de Foucault, su imbricación en el contexto de la modernidad es profunda y bastante compleja. De ahí que el autor señale en su texto sobre la llustración cómo, a pesar de que la gran promesa de la modernidad temprana (siglo XVIII) fue la de incrementar la libertad de los individuos de manera proporcional al crecimiento de nuestra capacidad técnica para manipular las cosas, las intervenciones técnicas del ser humano que han tenido por objeto desplegar nuestra autonomía (en los ámbitos de la economía, de la medicina, de las instituciones sociales y políticas, los medios de comunicación, etc.) a menudo han decantado en procedimientos de normalización, en la ampliación de la capacidad estatal para coaccionar a los individuos y otras formas de prácticas opresivas (Foucault 1994, 16). 


\section{$\S 2$. Habermas y el ideal de la racionalidad comunicativa como el proyecto inacabado de la modernidad}

Habría un contraste importante entre el proyecto crítico de Foucault y el de Jürgen Habermas. Es conocida la frase de Habermas en la que se refiere a la modernidad como "un proyecto inacabado". Donde Foucault es abierto en su desconfianza ante la idea de grandes transformaciones sociales propias de las grandes narrativas modernas, prefiriendo las transformaciones locales antes descritas (Foucault 1994, 14-15), Habermas se movería en el registro de una comprensión más clásica de la modernidad. Ahora bien, el alemán compartiría con Foucault la intención de escapar de los grandes sistemas metafísicos y de las concepciones teleológicas de la historia heredados de la filosofía moderna; Habermas es claro, desde el inicio de su gran obra, la Teoría de la acción comunicativa, al sostener que su proyecto busca ser una filosofía "postmetafísica". Sobre esto volveré más adelante. Por lo pronto, me aventuraré a señalar que podemos comprender las ideas habermasianas sobre la modernidad y la llustración a partir de un cierto hecho histórico o, más bien, del resultado de una confluencia de hechos históricos que, siguiendo a Weber, habrían llevado a un "descentramiento de la razón". Para Habermas, los procesos de aprendizaje técnico-científicos característicos de la modernidad habrían ido de la mano con un aprendizaje que él califica como "práctico-moral" (Habermas 1998, I21): no solo se habría ampliado nuestra capacidad para manipular la naturaleza, sino que se habría escindido de este ámbito objetivo un segundo espacio de razones que no referirían a una concatenación de causas y efectos empíricos, sino a normas de conducta intersubjetivamente reconocidas. Tal concepción de las normas contrasta con las concepciones mítico-religiosas y metafísicas del mundo, en las que no habría una delimitación adecuada de las normas del mundo social y los fenómenos del mundo natural ${ }^{16}$. Asimismo, la descentración de la razón daría lugar a una distinción entre tres distintos "mundos" o sistemas de referencia: un mundo objetivo regido por causas naturales, un mundo social regido por normas de conducta intersubjetivamente reconocidas y un mundo subjetivo de vivencias personales. Así pues, el saber racional de las sociedades modernas no se limitaría a un saber teórico de

I6 De hecho, Habermas va más allá: para él, en las concepciones premodernas del mundo no habría una adecuada separación entre el mundo y la propia concepción del mundo, reflejada en el lenguaje (Habermas 1998, 78). 
carácter cognitivo-instrumental, sino que habría también saberes prácticos de carácter moral y expresivo, respectivamente.

Como se ha dicho, el saber del primer tipo (cognitivo-instrumental) implicaría una aproximación al mundo en tanto mundo de hechos, de objetos ordenados según relaciones de causa y efecto, descrito y explicado de acuerdo a esas relaciones y manipulado en función de las mismas; esta forma de aproximarse a las cosas implicaría criterios de verdad (la descripción y/o explicación adecuada de los estados de cosas) y de eficiencia (obtener resultados adecuados a partir de nuestro conocimiento de dichos estados de cosas). El saber del segundo tipo (práctico-moral), por su parte, implicaría la aproximación al mundo como mundo social y podría fundarse en criterios de verdad o eficiencia, pero, en tanto que ahí se establecerían relaciones interpersonales regidas normativamente, tendría que funcionar de acuerdo a criterios de corrección normativa (una vez más, regirse de acuerdo a normas o principios morales que todos los individuos de dicho espacio social pudieran reconocer como legítimas). Finalmente, el saber práctico-expresivo daría cuenta del propio mundo subjetivo y se regiría por criterios de "veracidad" o "autenticidad": uno tendría que poder fundamentar la autenticidad de sus vivencias particulares ante los demás. Estos distintos criterios son englobados por Habermas bajo la categoría general de "pretensiones de validez" (Habermas 1998, 6I-69, I2I-I36) 17. Lo interesante es que, para este autor, a la base de la racionalidad humana no se hallaría, por dar un ejemplo, una racionalidad de tipo instrumental como la que se aprecia en la relación con el mundo objetivo, ni una racionalidad orientada a la valoración como la que se da en el mundo social, sino más bien una "racionalidad comunicativa", una forma de acción que no respondería a una lógica teleológica sino a un entendimiento mutuo, "incondicionado", que sería la condición de posibilidad de toda actividad colectiva (Habermas 1998, 136-146). Por ello, lo que sostendría el mundo de la vida sociocultural de los individuos capaces de lenguaje y acción sería el acuerdo lingüístico intersubjetivo sobre los contenidos en cada uno de los tres sistemas de referencia (sobre los hechos objetivos, las normas moralmente aceptables, etc.). Dicho acuerdo estaría basado exclusivamente en los contenidos semánticos de los

17 Habermas es tajante sobre lo siguiente: los tres mundos no serían mundos ontológicamente diferenciados, sino espacios de razones articulados según distintas lógicas, distintas pretensiones de validez susceptibles de crítica. 
saberes (teórico y prácticos) históricamente constituidos y en los compromisos pragmáticos que dichos contenidos implican (por ejemplo, qué implicaría mi afirmación de que cierto animal es un mamífero o prometer a mis compañeros que llegaré temprano a una reunión de trabajo, etc.). Ahora bien, mis palabras y mis actos siempre pueden ser cuestionados por los otros miembros de la comunidad de hablantes, lo que me forzaría a apelar a los contenidos de alguno de los tres mundos a modo de razones o justificaciones; de no considerar mis justificaciones como válidas, mis expresiones y acciones serán rechazadas. Por ello, la estructura de la racionalidad (comunicativa) tendría un carácter eminentemente crítico, en tanto que la posibilidad de los individuos dueños de lenguaje y acción de problematizar los contenidos de su mundo compartido siempre estaría abierta. Que la crítica lleve o no a una transformación de dicho mundo dependería únicamente de la capacidad racional para justificarse (Habermas 1998, 104).

Debido a que lo que determina la validez de las razones empleadas será exclusivamente el nexo semántico-pragmático contenido en los actos de habla (ilocucionario), y no sus efectos fácticos sobre la realidad empírica (perlocucionarios), podríamos considerar el ámbito de la racionalidad comunicativa, que hace posible la acción concertada de los individuos y su oposición a un uso estratégico-instrumental de la razón que solo busca manipular el mundo exterior en la teoría de Habermas, como una reinterpretación de la oposición kantiana entre un espacio autónomo incondicionado y uno heterónomo condicionado (Habermas 1998, 35I-432). Para el autor de Frankfurt, esta posibilidad de abrir canales de comunicación en los que no interfieran efectos perlocucionarios, reduciendo al mínimo la influencia de coacciones que no derivasen su fuerza del peso de las buenas razones en las relaciones interpersonales, sería el verdadero legado de la modernidad; la realización de dicha posibilidad, sería su proyecto inacabado.

Es esta separación entre la validez normativa y la facticidad empírica como un ámbito autónomo y uno heterónomo respectivamente lo que lleva a Habermas a realizar una serie de críticas al proyecto de Foucault. A juicio del alemán, Foucault partiría de una errada pretensión de neutralidad en sus análisis tanto arqueológicos como genealógicos, conjurando todo tipo de compromiso con criterios normativos claros; esta fría mirada de carácter positivista, insiste, le llevaría a disolver toda pretensión de validez para exponer la condición 
fáctica de las relaciones de poder. Esto invalidaría toda posible valoración de las prácticas sociales, quitándole al genealogista todo suelo desde el cual justificar sus críticas: “(...) a medida que se restringe a una objetividad vacía de toda reflexión, a una descripción del cambio caleidoscópico de prácticas de poder, que ascéticamente renuncia a toda participación siquiera sea virtual, la historiografía genealógica se delata como la seudociencia presentista, relativista y criptonormativista que no quiere ser" (Habermas 2008, 30I). Para Habermas, la pretendida objetividad de Foucault lo llevaría, irónicamente, a un "incurable subjetivismo". Asimismo, puesto que todo contrapoder se movería a priori sobre el horizonte de un poder omnipresente, surgiría la cuestión sobre por qué sería preferible la lucha a la sumisión (Habermas 2008, 306) ${ }^{18}$. Un último punto de la crítica de Habermas a Foucault sería que, puesto que se ha reducido el espacio social a pura facticidad, la perspectiva genealógica solo podría concebir acciones de tipo estratégico (en un sentido de estrategia muy distinto del de Foucault); esto es, los individuos solo podrían actuar con la satisfacción de sus intereses individuales en la mira y no podrían entablar acuerdos basados en mutuo entendimiento; no podrían tratarse como sujetos autónomos, capaces de responder a razones, sino como cosas disponibles para su manipulación (Habermas 1998, 126-127). Asimismo, esto acabaría en una concepción inadecuada de los procesos de subjetivación que, a juicio de Habermas, pasarían necesariamente por el medio de la comunicación lingüística: “(...) la socialización de los sujetos capaces de lenguaje y de acción no puede entenderse al mismo tiempo como individuación, sino únicamente como una progresiva subsunción de los cuerpos, de los sustratos vivos bajo tecnologías del poder. (...) [S]e echa en falta un mecanismo de integración social como el lenguaje (con el entrelazamiento de actitudes realizativas de hablantes y oyentes) que pudiera explicar el efecto individuante que la socialización tiene" (Habermas 2008, 313).

Dejaremos las respuestas a las críticas de Habermas para las conclusiones del presente trabajo. Por lo pronto, recapitulemos: la modernidad, para

I8 Nancy Fraser, a quien Habermas cita, es bastante enfática sobre este punto: "iPor qué es preferible la lucha a la sumisión? ¿Por qué debemos oponernos a la dominación? Sólo introduciendo algún tipo de nociones normativas podría Foucault empezar a dar respuesta a esta pregunta. Sólo introduciendo nociones normativas podría empezar a decirnos qué es lo que está mal en el moderno régimen de poder/conocimiento y por qué debemos oponernos a él (...)" (Habermas 2008, 309). 
Habermas, habría liberado un potencial comunicativo inusitado, en tanto que la concepción moderna del mundo se sostendría sobre razones cuya validez sería permanentemente susceptible de crítica. Por ello, el ideal de las sociedades modernas sería el de una sociedad cuyas estructuras estarían siempre abiertas a la posibilidad de transformarse en la medida en que surjan nuevos aprendizajes sociales (es decir, en la medida en que surjan nuevas y mejores razones que legitimen, en un proceso crítico, la modificación de las estructuras actuales). Por esta razón, la teoría social de Habermas estaría comprometida incuestionablemente con la posibilidad de un progreso histórico. De lo que se trataría sería de garantizar las condiciones de estos procesos de crítica e intercambio de razones sin que haya interferencias heterónomas por parte de racionalidades de carácter teleológico que instrumentalicen el potencial racional de la modernidad.

\section{$\S 3$. Conclusiones}

En buena medida, las críticas de Habermas a Foucault no se sostienen. Esto se debe a que Habermas parte de una comprensión del poder como mera coacción o dominación. Como hemos visto, la concepción relacional del poder que mantiene Foucault es de un carácter predominantemente constitutivo (del mismo modo que la racionalidad instrumental para Habermas es parasitaria de la racionalidad comunicativa, para Foucault la dominación o poder coactivo en cierto modo sería parasitaria del poder pastoral ontológico); en los análisis del francés, una norma puede ser perfectamente legítima o una proposición puede ser indiscutiblemente verdadera, y no por ello dejarían de estar imbricadas en haces de relaciones de poder. Si bien el poder tiene una faz negativa, no siempre sería el caso. Asimismo, la distinción entre una subjetivación pasiva y una activa nos revelaría un cierto criterio normativo en el aparato crítico foucaultiano. La distinción de raigambre kantiana entre un ámbito racional incondicionado y uno fáctico condicionado de la que parte Habermas sería, cuando menos, problemática (cuando no altamente idealista).

Sin embargo, también podríamos hacer críticas a la concepción histórica de Foucault desde la mirada habermasiana. $Y$ es que el francés descuidaría en exceso el ámbito de lo semántico y su estrecha relación con los compromisos pragmáticos asumidos en las interacciones sociales. La apropiación 
estratégica de las normas que se expresa en la resistencia al poder parecería remitirnos a una ontología vitalista en la que la singularidad de la vida escapa permanentemente del constreñimiento de normas abstractas. El criterio de la dinamicidad del poder (en oposición a su rigidización en la forma de la dominación) sería demasiado amplio (quizá incluso demasiado formal): el aparato crítico de Foucault no permitiría especificar qué formas de vida, qué tipos de resistencia al poder serían legítimos. Es cierto que los trabajos genealógicos de Foucault suelen tomar posición a favor de minorías oprimidas, víctimas de la normalización institucional, etc., pero las dinámicas de poderes y contrapoderes que describe podrían usarse para explicar sin problemas la resistencia de un grupo extremista, racista u homofóbico a la institucionalidad estatal; a mi juicio, no queda claro por qué una lucha de estas características sería ilegítima desde el esquema foucaultiano. Incluso si se apela al hecho de que la resistencia de dicho grupo afectaría negativamente a otros grupos oprimidos (generando una dinámica de poder y resistencia), dicha comprensión agonística de lo social acabaría pareciéndose por momentos a una concepción darwinista de la sociedad.

Creo que es esta misma desconsideración de la conexión entre semántica y pragmática la que lleva a Foucault a entender los contextos epistémicos como unidades que por momentos parecen inconmensurables una respecto a otras. La idea de que obramos en el presente a partir de saberes heredados, históricamente constituidos, no sería tan fácilmente descartable (lo que Habermas llama “procesos de aprendizaje”). Piénsese, por dar un ejemplo, en cómo todo avance en la matemática contemporánea presupone el desarrollo por parte de los matemáticos griegos de la noción de factorización. Por supuesto, es pertinente señalar que los griegos tenían una comprensión del mundo (que abarcaba su saber matemático) muy diferente de la nuestra, pero eso no quita que sería imposible pensar en la matemática contemporánea sin las innovaciones propias de ese período. En ese sentido concreto creo que es inevitable hablar, con Habermas, de un aprendizaje social (que no tendría por qué estar limitado al saber teórico: incluso habiendo triunfado alguien como Donald Trump en las últimas elecciones estadounidenses, la indignación generalizada al respecto es algo que, muy probablemente, no hubiera sucedido si alguien con su perfil hubiera llegado a la presidencia en la década de 1920) y de la necesidad de criterios que nos permitan evaluar progresos y retrocesos en el mundo humano. Para esto no tendríamos que asumir el dualismo habermasiano entre 
ámbitos instrumentales y comunicativos, negando los elementos contingentes y agonísticos que cumplen un rol en la constitución de nuestro saber; pero sí habría que pensar en la capacidad de los seres racionales de reconstruir (siempre desde nuestro presente, siempre retroactivamente; es decir, siempre involucrados en los hechos concretos), a modo de jurisprudencia histórica, la marcha intrincada del elemento racional en la historia.

El filósofo norteamericano Robert Brandom propone un concepto útil para aclarar algo más este punto: se trataría de una "hermenéutica de la magnanimidad”. Para Brandom, la forma en que aplicamos nuestros conceptos en el presente tomaría la historia de las aplicaciones pasadas de aquellos como precedentes, declarando (retroactivamente) algunos de esos usos previos como válidos y otros como inválidos, transformando sus contenidos en ese proceso. De ese modo, al aplicar un concepto en el presente, reconociendo ciertos usos pasados de este como correctos y otros como incorrectos, uno reconoce la "autoridad" de la tradición que le ha sido heredada, haciéndose responsable ante ella y, al mismo tiempo, estableciendo su autoridad sobre la tradición que deja tras de sí, quedando a la espera de que los sujetos futuros reconozcan o anulen sus decisiones. Como ejemplo podríamos usar el concepto ilustrado de "igualdad": en sus orígenes, habría sido pensado para una comunidad de hombres blancos europeos; sin embargo, tomando un caso real, Rosa Parks, siendo una mujer negra en el contexto del segregacionismo racial estadounidense de los años 50 s, al no ceder su asiento al hombre blanco que se lo exigía, crea un precedente normativo y actualiza el sentido del concepto de igualdad (independientemente de las razones contingentes por las que Parks haya decidido no ceder el asiento, podemos reconstruir retroactivamente la racionalidad implícita en el concepto de igualdad de tal modo que entendamos su acción como un uso legítimo de dicho concepto, explicitando las contradicciones en las que incurrían los partidarios del segregacionismo). Lo que se reconstruye de esta manera es una narrativa progresiva en la que las contingencias de las prácticas discursivas heredadas van ordenándose, revelándose cierta racionalidad (cierta normatividad) que en cierto sentido siempre estuvo implícita en el pasado (Brandom 2013a, 92-94). En palabras de Hegel, se le daría a la contingencia la forma de la necesidad ${ }^{19}$;

19 De modo inverso a la genealogía, que disuelve la necesidad en la contingencia. 
en las de Brandom, se convierte un pasado en una historia. La ganancia que ofrece esta forma de aproximarse a la racionalidad histórica, frente a la genealogía foucaultiana, es que mantiene un criterio normativo definido que impediría que cualquier particularidad busque imponerse arbitrariamente sobre el contenido de las normas, pero que permite la legítima vindicación de un número de luchas al refinarse o reinterpretarse históricamente estos contenidos (Brandom 2013b, 14-19).

\section{Bibliografía}

Brandom, R., 1979. Freedom and Constraint by Norms. American Philosophy Quarterly 16 (3), 187-196.

-2013a. Reason in Philosophy: Animating Ideas. Cambridge, Mass.: Harvard University Press.

- 2013b. Reason, Genealogy and the Hermeneutics of Magnanimity. Conferencia presentada en Howison Lectures on Philosophy. Universidad de California. Berkeley, 13 de marzo de 2013. http://www.pitt.edu/ brandom/downloads/RGHM\%20\%20 |2-II-2|\%20a.docx. Consultado 3 de octubre de 2017.

Dreyfus, H.yP. Rabinow, 1983. Michel Foucault: Beyond Structuralism and Hermeneutics. Chicago: The University of Chicago Press.

Foucault, M., 1988. El sujeto y el poder. Traducción de Corina de Iturbe. Revista Mexicana de Sociología 50 (3), 3-20. https://doi.org//0.2307/354055।

- 1992. Microfísica del poder. Traducción de Julia Varela y Fernando Álvarez-Uría. Madrid: Endymión.

— 1994. ¿Qué es la llustración?. Traducción de Jorge Dávila. Revista Actual 28, I-18.

- 1999a. La ética del cuidado de sí como práctica de la libertad. En: Ética, estética y hermenéutica. Traducción de Ángel Gabilondo. Barcelona: Paidós, 393-415.

— 1999b. Estrategias de poder. Traducción de Fernando Álvarez Uría y Julia Varela. Barcelona: Paidós.

- 2002. La arqueología del saber. Traducción de Aurelio Garzón del Camino México D.F.: Siglo XXI.

-2008. Historia de la sexualidad I: La voluntad de saber. Traducción de Ulises Guiñazú. Buenos Aires: Siglo XXI.

Gutting, G., 1989. Michel Foucault's Archaeology of Scientific Reason. Nueva York: Cambridge University Press. https://doi.org//0.1017/CBO978II39172141

Habermas, J., 1998. Teoría de la acción comunicativa l: Racionalidad de la acción y racionalización social. Traducción de Manuel Jiménez Redondo. Madrid: Taurus.

- 2008. El discurso filosófico de la modernidad. Traducción de Manuel Jiménez Redondo. Buenos Aires: Katz. 
Han, B. y E. Pile, 2005. The Analytic of Finitude and the History of Subjectivity. En: The Cambridge Companion to Foucault, ed. G. Gutting. Nueva York: Cambridge University Press, 179-209. https://doi.org/10.1017/CCOL0521840821.008

Ingram, D., 2005. Foucault and Habermas. En: The Cambridge Companion to Foucault, ed. G. Gutting. Nueva York: Cambridge University Press, 240-283. https://doi. org/I0.1017/CCOL052I84082I.010

Owen, D., 1999. Orientation and Enlightenment: An Essay on Critique and Genealogy. En: Foucault Contra Habermas, eds. S. Ashendeny D. Owen. Londres: Sage Publications, 2I-44. https://doi.org//0.4135/9781446221822.n2

— 2008. Nietzsche, Ethical Agency and the Problem of Democracy. En: Nietzsche, Power and Politics: Rethinking Nietzsche's Legacy for Political Thought, eds. H. Siemens y V. Roodt. Berlín: Walter de Gruyter, 143-167.

Rouse, J., 2005. Power/Knowledge. En: The Cambridge Companion to Foucault, ed. G. Gutting. Nueva York: Cambridge University Press, 95-122.

Saar, M., 2008. Understanding Genealogy: History, Power, and the Self. Journal of the Philosophy of History 2, 295-3I4. https://doi.org//0.1I63//87226308X335976

Wartenberg, T., 1990. The Forms of Power: From Domination to Transformation. Philadelphia: Temple University Press. 